\title{
Formulation, Development and Evaluation of Etoricoxib Nanosize Microemulsion Based Gel for Topical Drug Delivery
}

\author{
Vania Rachael Fonseca, Prashant Jivaji Bhide*, Madhusudan Purushottam Joshi \\ Department of Pharmaceutics, Goa College of Pharmacy, $18^{\text {th }}$ June Road, Panaji, Goa, INDIA.
}

\begin{abstract}
Introduction: Etoricoxib is a poorly water-soluble oral NSAID and is associated with a number of complications such as bleeding, ulcers and dyspepsia but these can be overcome by delivering the drug topically. Objectives: Microemulgel for the topical delivery of etoricoxib was formulated to increase its solubility and thus improve the skin permeability. Methods: The solubility of etoricoxib was studied in various oils, surfactants and cosurfactants. Pseudo-ternary phase diagrams were constructed by varying the surfactant to cosurfactant (Smix) ratio. Microemulsions with different compositions were formulated and optimized. Selected o/w microemulsions contained $1 \%$ etoricoxib and were evaluated for $\mathrm{pH}$, rheology, drug content, particle size and in vitro drug release. Optimized microemulsion was incorporated in $1 \%$ Carbopol $^{\circledR} 934$ and was evaluated for rheological properties, spreadability, in vitro permeation, skin irritation and stability. Results: Capryol ${ }^{\top M} 90$, Tween 80 and Transcutol $^{\circledR}$ P exhibited the highest solubility. Maximum microemulsion region was observed when the Smix ratio was 3:1. The average particle size of the optimized microemulsion was $37.61 \mathrm{~nm}$, zeta potential was $-2.88 \mathrm{mV}$ and permeability of the drug from the microemulsion was $66.8 \%$ after $8 \mathrm{~h}$. The prepared gel showed $57.8 \%$ drug release after $8 \mathrm{hr}$. Skin irritation studies indicated that the optimized formulation was safe for topical application. Stability studies indicated that the formulation remained unaffected at accelerated storage conditions. Conclusion: Results indicated that the micro-emulgel has potential for sustained action of drug release and may act as a promising tool to enhancepercutaneous delivery of etoricoxib.
\end{abstract}

Key words: Etoricoxib, Microemulsion, Topical gel, in vitro release, Particle size, Skin irritation.

\section{INTRODUCTION}

Rheumatoid arthritis is a chronic, systemic inflammatory disease that affects nearly $1 \%$ of the world's adult population and results in the destruction of the joints thereby significantly impairing the quality of life of the patient. ${ }^{1}$ This disease is two to three times more likely to affect women than men and can occur at any age, but mostly it starts at middle age. ${ }^{2}$ Osteoarthritis, a chronic disease involves both cartilage and bone and results from an imbalance in erosive and reparative processes. Gout represents a heterogeneous group of diseases that are caused by an inflammatory response to the formation of monosodium urate crystals which develop secondary to hyperuricemia. ${ }^{3}$

Etoricoxib (ETO) is a non-steroidal antiinflammatory drug indicated for the symptomatic relief of rheumatoid arthritis, osteoarthritis and gout. ${ }^{4}$ It belongs to Class II category under the Biopharmaceutical Classification System. ${ }^{5}$ It is available in the form of oral tablets. Major side-effects include: gastrointestinal ulcers, bleeding on chronic use and possibly anemia. ${ }^{6}$

The use of microemulsions as potential drug delivery vehicles has attracted considerable interest due to their ease of prepara-
Submission Date: 21-02-2019; Revision Date: 04-09-2019; Accepted Date: 28-10-2019

DOI: 10.5530/ijper.53.4s.152 Correspondence: Dr. Prashant Bhide, Professor, Goa College of Pharmacy, 18th June Road, Panaji-403001, Goa, INDIA. Phone: +91 08322226882 E-mail: pjbhide_2000@yahoo. com

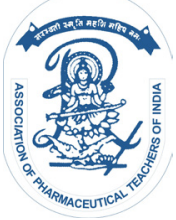

www.ijper.org 
tion, clarity, thermodynamic stability, low viscosity, small droplet size and the ability to incorporate hydrophilic as well as hydrophobic drugs. ${ }^{7}$ Most of the drugs, when given by oral route, have side effects such as gastric irritation, nausea, bleeding in the gastrointestinal tract, etc. The topical route of administering such drugs is a substitute, thereby reducing their side effects. ${ }^{8}$

Many of the widely used topical agents such as ointments, creams and lotions are associated with a number of disadvantages. They cause uneasiness to the patient when applied due to their sticky nature and need to be applied with rubbing as they have a lower spreading coefficient.

They also exhibit the problem of stability. Due to these limitations, the use of transparent gels in pharmaceutical preparations has increased. The major disadvantage of gels is their inability to deliver water-insoluble drugs. A hydrophobic drug cannot be directly incorporated into a gel base therefore microemulsion based approach is used so that the drug can be successfully incorporated into a gel-based system. The oil-in-water microemulsion is first prepared and evaluated and then incorporated into a gel base and this dosage form is referred to a microemulsion based gel. It is more advantageous as compared to conventional topical formulations. ${ }^{9}$

In the literature, cream and gel of etoricoxib were developed in order to overcome the toxicities associated with oral administration of the drug. ${ }^{10,11}$ Polymeric nanoparticles, ethosomes and poly (caprolactone) microparticles (MPs) loaded composite injectable chitosan gel were formulated for the topical delivery of etoricoxib. ${ }^{12-14}$ Mouth dissolving films of etoricoxib as an alternative to oral disintegrating tablets due to its ease of administration and better patient compliance. ${ }^{15}$ Lala and Awari developed nanoemulsion-based gel improved transdermal delivery of etoricoxib. ${ }^{16}$

In this study, a topical microemulsion based gel of etoricoxib was formulated in order to minimize the side effects associated with the oral delivery of the drug. The formulated microemulsion based gel was then evaluated.

\section{MATERIALS AND METHODS}

\section{Materials}

Etoricoxib was obtained as a gift sample from Sanofi India Limited (Verna, Goa, India). Capryol ${ }^{\mathrm{TM}} 90$ and Transcutol ${ }^{\circledR}$ P were gifted by Gatefosse' (India). Cremophor ${ }^{\mathbb{R}}$ RH 40 was received as a gift sample from Centaur Pharmaceuticals Ltd., (Goa, India). Oleic acid, castor oil, isopropyl myristate, olive oil, Tween 20, Tween 80, polyethylene glycol 600 , polyethylene glycol 400 , isopro- pyl alcohol, ethanol and propylene glycol were obtained from standard sources. The dialysis membrane was purchased from Himedia (India). All the other chemicals used were of analytical grade.

\section{Screening of oils, surfactants and cosurfactants on the basis of solubility study}

The components selected for the formulation of the microemulsions were of pharmaceutical grade, nonirritating and non-sensitizing to the skin and fall under the Generally Recognized as Safe (GRAS) category. The surfactants were chosen based on their Hydrophilic Lipophillic Balance (HLB) value and were non-toxic in nature. The cosurfactant forms a stable microemulsion with the surfactant at a minimum concentration. ${ }^{17}$ Screening of the oils, surfactants and co-surfactants was done for etoricoxib solubility using the shake flask method..$^{18}$ An excess amount of drug was added to $5 \mathrm{~mL}$ of each of the oil, surfactant and cosurfactant in conical flasks and was placed on a mechanical shaker (Orbitek, India) at ambient temperature and humidity for $48 \mathrm{~h}$ at $100 \mathrm{rpm}$. The suspensions were filtered through $0.45 \mu$ membrane filters, diluted appropriately with methanol and the amount of drug dissolved was quantified using a UV-visible spectrophotometer (UV 3092, Labindia, India) against methanol as the blank at $235 \mathrm{~nm}$. The oil, surfactant and cosurfactant that showed the maximum solubility of etoricoxib (ETO) were selected for the formulation of the microemulsions. ${ }^{19}$

\section{Screening of the selected surfactant and cosurfactant for emulsification ability}

The efficacy of the surfactant and cosurfactant was assessed by the turbidimetric method ${ }^{19}$ to improve the ability of micro-emulsification. For screening of the surfactant, $300 \mathrm{mg}$ of surfactant was added to $300 \mathrm{mg}$ of the selected oil phase and heated at $45-60^{\circ} \mathrm{C}$ to aid in the homogenization of the components. For screening of the cosurfactant, $200 \mathrm{mg}$ of the surfactant and 100 $\mathrm{mg}$ of the cosurfactant was added to $300 \mathrm{mg}$ of the oil phase. This mixture was heated at $45-60^{\circ} \mathrm{C}$ to aid in homogenization. Then, $50 \mathrm{mg}$ of each of the isotropic mixture was diluted to $50 \mathrm{~mL}$ with distilled water in a volumetric flask to form a fine emulsion. The emulsions were allowed to stand for $2 \mathrm{hr}$ and their transmittance was measured at $650 \mathrm{~nm}$ using a UV-visible spectrophotometer against distilled water as the blank. ${ }^{20}$

\section{Construction of pseudo-ternary phase diagrams}

Pseudo-ternary diagrams were constructed by employing the water titration method ${ }^{21}$ to define the extent and nature of the microemulsion region. The surfactant and cosurfactant (Smix) were mixed in different volume 
ratios $\left(\mathrm{K}_{\mathrm{m}}\right)$ i.e., 1:1, 2:1 and 3:1. The ratio of oil and Smix were varied for each phase diagram i.e., 9:1 to 1:9 $(\mathrm{v} / \mathrm{v})$. To each of the oil: Smix mixture, water was added drop-wise under magnetic stirring at ambient temperature and was examined for appearance after each addition. The point where the solution turned turbid or cloudy was the end point of the titration. The volume of water required to make the mixture turbid or cloudy was noted. Pseudo-ternary diagrams were constructed using CHEMIX School 7.00 software. The percentages of the components were calculated and plotted on the pseudo-ternary phase diagram. The points were joined and a boundary between the clear and turbid region was defined. ${ }^{22}$

\section{Formulation and development of blank microemulsions}

The ratio of the surfactant and cosurfactant was selected from the pseudo-ternary phase diagrams and the o/w microemulsion region was identified. The microemulsions were formulated at definite component ratios i.e. 5-30\% for oil, 30-65\% for Smix and 35-65\% for water. The surfactant, cosurfactant and oil in which the drug had maximum solubility were mixed with continuous magnetic stirring (Remi, India). Fresh deionized water was added drop wise to this uniform blend and mixed well for $30 \mathrm{~min}$ to form a transparent microemulsion. The formulations were then evaluated. ${ }^{23}$

\section{Formulation of etoricoxib loaded microemulsions}

The blank microemulsions were prepared first and checked for stability. Stable blank formulations were then used to formulate microemulsions containing the drug. The drug containing microemulsions were prepared by dissolving accurately weighed etoricoxib in the oil and Smix at room temperature. Water was added dropwise to this mixture with constant stirring at ambient temperature. The micro-emulsions were allowed to equilibrate for $30 \mathrm{~min}$ with gentle magnetic stirring. The formed microemulsions were then evaluated after $24 \mathrm{hr}$. The compositions of the microemulsions are tabulated in Table 1.

\section{Evaluation of blank and etoricoxib loaded microemulsions}

The blank and drug loaded formulations were evaluated for clarity and appearance, quantitative tests (dilution and dye test), percent transmittance, viscosity, $\mathrm{pH}$ and centrifugation. Drug loaded formulations were also evaluated for drug content, droplet size, polydispersity and zeta potential. In all the tests, the results were recorded in triplicate and the average was considered.

\begin{tabular}{|c|c|c|c|}
\hline Formulation & Oil (\% v/v) & Smix (\% v/v) & Water (\% v/v) \\
\hline M5 5\% & 5 & 50 & 45 \\
\hline M6 5\% & 5 & 55 & 40 \\
\hline M7 5\% & 5 & 60 & 35 \\
\hline M4 10\% & 10 & 45 & 45 \\
\hline M5 10\% & 10 & 50 & 40 \\
\hline M6 10\% & 10 & 55 & 35 \\
\hline
\end{tabular}

The prepared microemulsions were visually evaluated for their color, homogeneity, consistency and physical changes such as phase separation or precipitation.

Dilution test and dye test were performed to determine whether the formulated microemulsions were w/o or o/w type.

The microemulsions were diluted 10, 100 and 1000 times with distilled water and visually examined for clarity, phase separation and drug precipitation.

A water-soluble dye (methylene blue) was added to the microemulsion and was visually observed for its distribution after $5 \mathrm{~min}$. A rapid dispersion of the water-soluble dye indicates that the microemulsion is $\mathrm{o} / \mathrm{w}$ type whereas a w/o type of microemulsion provides microscopically visible droplets.

The optical clarity of the microemulsions was determined by measuring the percent transmittance of the formulated microemulsions using a Ultraviolet (UV) visible spectrophotometer at $650 \mathrm{~nm}$ against distilled water as the blank. The percent transmittance of the diluted microemulsions at 10,100 and 1000 times with the continuous phase was measured in the same manner.

The viscosity was measured using a Brookfield ${ }^{\circledR}$ viscometer (DVE, Brookfield, USA). The spindle number 62 was dipped in the microemulsion and was rotated at $20 \mathrm{rpm}$ at ambient temperature.

The $\mathrm{pH}$ of the drug loaded microemulsions was measured using a calibrated digital $\mathrm{pH}$ (1010, Esico, India) meter at ambient temperature.

Microemulsion equivalent to $10 \mathrm{mg}$ of etoricoxib was taken in a $10 \mathrm{~mL}$ volumetric flask and was extracted using methanol as the solvent. The volume was made up to $10 \mathrm{~mL}$ with methanol. The absorbance of the solution was measured after suitable dilution using a UV-visible spectrophotometer at $235 \mathrm{~nm}$ and the concentration of the drug was calculated.

The microemulsions were centrifuged at $5000 \mathrm{rpm}$ for $10 \mathrm{~min}$ at ambient temperature and the systems were visually examined for creaming and phase separation. 
The droplet size, polydispersity index and zeta potential of the microemulsions were measured using a particle size analyzer (Zetasizer zen 3600, Malvern, UK).

\section{In vitro drug release}

In vitro drug release study of etoricoxib was carried out using a modified Franz diffusion cell. ${ }^{16}$ The semipermeable membrane was previously soaked overnight in phosphate buffer $\mathrm{pH} 7.4$ and was mounted between the donor and receptor compartment. The active diffusion area of the cell was $4.91 \mathrm{~cm}^{2}$. Microemulsion equivalent to $10 \mathrm{mg}$ of etoricoxib was placed in contact with the dialysis membrane of the donor compartment. The receiver compartment contained $25 \mathrm{~mL}$ of phosphate buffer $\mathrm{pH} 7.4$ and was stirred at $100 \mathrm{rpm}$ using a magnetic stirrer throughout the duration of the experiment. The temperature of the assembly was maintained at 37 $\pm 2^{\circ} \mathrm{C}$. One $\mathrm{mL}$ of the fluid from the receptor compartment was periodically withdrawn every one hour up to $8 \mathrm{~h}$ and was immediately replaced by an equal volume of receiver fluid. The concentration of the drug in the receptor compartment was determined spectrophotometrically at $234 \mathrm{~nm}$ after suitable dilution with phosphate buffer $\mathrm{pH} 7.4$ using the same as the blank. ${ }^{24}$

\section{Stability studies}

The stability studies were performed in accordance with the ICH guidelines. ${ }^{25}$ The stability of the optimized microemulsion was monitored at $40^{\circ} \mathrm{C} / 75 \% \mathrm{RH}$ for 3 months. It was inspected and evaluated for physical stability, percent transmittance, viscosity, $\mathrm{pH}$, drug content and in vitro drug release.

\section{Formulation and development of etoricoxib microemulsion based gel}

The low viscosity of microemulsions restricts its application and this disadvantage can be overcome by incorporating them in gelling agents. The optimized drug loaded microemulsion was selected to formulate the etoricoxib microemulsion based gel. Carbopol ${ }^{\circledR} 934$ was selected as the gelling agent based on previous studies. $1 \% \mathrm{w} / \mathrm{w}$ of the gelling agent was soaked in water for 24 hr. The $\mathrm{pH}$ of the Carbopol ${ }^{\mathbb{B}} 934$ gel was adjusted to 6-7 by the dropwise addition of triethanolamine. The microemulsion based gel was prepared by adding the optimized microemulsion to the gel base.

\section{Evaluation of etoricoxib microemulsion based gel}

The gel was evaluated for physical appearance, viscosity, $\mathrm{pH}$, spread ability and drug content, in all the tests, the results were recorded in triplicate and the average was considered.
The microemulsion based gel was visually examined for its appearance, color, consistency, homogeneity, texture, etc.

The viscosity of the microemulsion based gel was measured using a DVE, Brookfield Viscometer. The spindle number 64 was dipped in the formulation and was rotated at $20 \mathrm{rpm}$ at ambient temperature.

The $\mathrm{pH}$ of a $1 \%$ aqueous solution of the microemulsion based gel was measured using a digital $\mathrm{pH}$ meter.

The spread ability of the etoricoxib microemulsion based gel was determined as per the procedure described by Bachhav, et al. $0.5 \mathrm{~g}$ of the microemulsion based gel was placed within a $1 \mathrm{~cm}$ diameter circle premarked glass plate over which a second glass plate was placed. A $5 \mathrm{~g}$ weight was allowed to rest on the upper glass plate for 5 min. The increase in diameter of the micro-emulgel due to spreading was noted. ${ }^{26}$

Microemulsion based gel, equivalent to $10 \mathrm{mg}$ of etoricoxib was taken in a $10 \mathrm{~mL}$ volumetric flask and was dissolved in methanol. The volume was made up to 10 $\mathrm{mL}$ with methanol. The absorbance of the solution was measured after suitable dilution using a UV-visible spectrophotometer at $235 \mathrm{~nm}$ and the concentration of the drug was calculated.

\section{In vitro release study}

In vitro drug release study of etoricoxib loaded microemulsion based gel was carried out using a modified Franz diffusion cell with an active diffusion area of 4.91 $\mathrm{cm}^{2}$. The membrane which was previously soaked overnight in phosphate buffer $\mathrm{pH} 7.4$ was mounted between the donor and receptor compartment. The $1 \mathrm{~g}$ of the drug loaded microemulsion based gel equivalent to 10 $\mathrm{mg}$ of etoricoxib was placed in contact with the dialysis membrane of the donor compartment. The receiver compartment contained $25 \mathrm{~mL}$ of phosphate buffer $\mathrm{pH}$ 7.4 and was stirred at $100 \mathrm{rpm}$ using a magnetic stirrer throughout the duration of the experiment. The temperature of the assembly was maintained at $37 \pm 2^{\circ} \mathrm{C}$. Then, $1 \mathrm{~mL}$ of the fluid from the receptor compartment was periodically withdrawn every one hour up to $8 \mathrm{~h}$ and was immediately replaced by an equal volume of receiver fluid. The concentration of the drug in the receptor compartment was determined spectrophotometrically at $234 \mathrm{~nm}$ after suitable dilution with phosphate buffer $\mathrm{pH} 7.4$ using the same as the blank.

\section{Kinetic modelling in vitro drug release results}

The results of in vitro studies were fitted in the zero order, first order, Higuchi and Korsmeyer-peppas kinetic models. 


\section{Ex vivo permeation study}

Ex vivo release studies were carried out on goat's pineal skin as the thickness of the skin over the pinna is less as compared to other parts. The hair was removed from the upper portion of the skin surface and the excised skin was thoroughly washed with distilled water and phosphate buffer $\mathrm{pH}$ 7.4. The permeation studies were performed using a modified Franz diffusion cell with an active diffusion area of $4.91 \mathrm{~cm}^{2}$. The excised skin was mounted between the two compartments with the stratum corneum facing the donor compartment. $25 \mathrm{~mL}$ of phosphate buffer $\mathrm{pH} 7.4$ was placed in the receiver compartment and stirred at $100 \mathrm{rpm}$. Then, $1 \mathrm{~g}$ of microemulsion based gel containing $1 \% \mathrm{w} / \mathrm{w}$ etoricoxib was placed in the donor compartment on the skin surface. The temperature of the assembly was maintained at $37 \pm 2^{\circ} \mathrm{C}$. One $\mathrm{mL}$ of the fluid from the receptor compartment was periodically withdrawn every one hour up to $8 \mathrm{hr}$ and was immediately replaced by an equal volume of receiver fluid. The concentration of the drug in the receptor compartment was determined spectrophotometrically at $234 \mathrm{~nm}$ after suitable dilution with phosphate buffer $\mathrm{pH} 7.4$ using the same as the blank. ${ }^{21}$

\section{Stability studies}

The stability of the microemulsion based gel was monitored at $40^{\circ} \mathrm{C} / 75 \% \mathrm{RH}$ for 3 months. The formulated microemulsions were visually inspected and evaluated for physical stability, viscosity, $\mathrm{pH}$, drug content and in vitro release.

\section{RESULTS AND DISCUSSION}

\section{Screening of the shortlisted oils, surfactants and cosurfactants}

Based on the criteria for the selection of the microemulsion components, oleic acid, isopropyl myristate, olive oil, castor oil and Capryol ${ }^{\mathrm{TM}} 90$ was selected as oils, Tween 20, Tween 80 and Cremophor ${ }^{\circledR}$ RH as surfactants and polyethylene glycol (PEG) 400, PEG 600, propylene glycol, ethanol and Transcutol ${ }^{\circledR} \mathrm{P}$ as cosurfactants. The saturation solubility of etoricoxib in various oils, surfactants and cosurfactants is shown in Figure 1. Among the selected oils, Capryol ${ }^{\mathrm{TM}} 90$ showed the maximum solubility while isopropyl myristate had the lowest solubility. Thus, Capryol ${ }^{\mathrm{TM}} 90$ was selected as the oil for further studies. The primary factor to be considered while selecting a surfactant is its safety. Ionic surfactants have been reported to be more toxic than non-ionic surfactants. ${ }^{27} \mathrm{~A}$ particular balance of low and high HLB surfactants is necessary to reduce the amount of surfactant used. Solubility of etoricoxib in Tween 80 was the highest among the surfactants. Transcutol ${ }^{\circledR} \mathrm{P}$ demonstrated highest solubility of etoricoxib as compared to the other tested cosurfactants.

\section{Screening of the selected surfactant and cosurfactant for its emulsification ability}

The percentage transmittance of the dispersions is given in Table 2. The emulsification study indicated that the surfactant Tween 80 had good ability to emulsify Capryol $^{\mathrm{TM}} 90$. The pseudo-ternary phase diagrams of Capryol $^{\text {TM }} 90$ with Tween 80 and Transcutol ${ }^{\circledR} \mathrm{P}$ at various $\mathrm{Km}$ ratios, i.e. 1:1, 2:1 and 3:1 is represented in Figure 2. The microemulsion area is represented by the colored potion in the phase diagram while the noncoloured portion represents the existence of a turbid and conventional emulsion. The phase diagram with the Smix ratio of 3:1 showed the highest area of emulsification and was therefore selected for further studies. It can be seen that an increase in the weight ratio of Tween 80 resulted in an expansion of the microemulsion region. This may be due to the reduction of the interfacial tension, increasing the fluidity of the interface and thereby increasing the entropy of the system. ${ }^{28}$

\section{Formulation and development of blank microemulsions}

The $\mathrm{o} / \mathrm{w}$ microemulsion region was identified in the pseudo-ternary phase diagram. A high concentration of

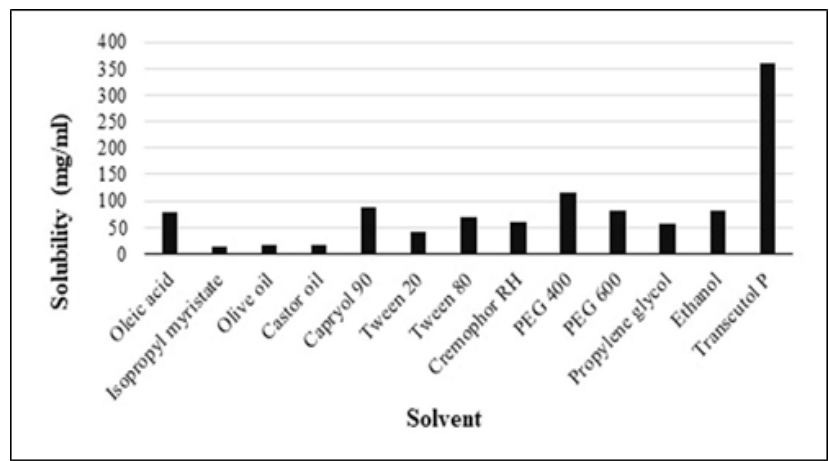

Figure 1: Bar graph indicating the solubility of ETO in various oils, surfactants and cosurfactants.

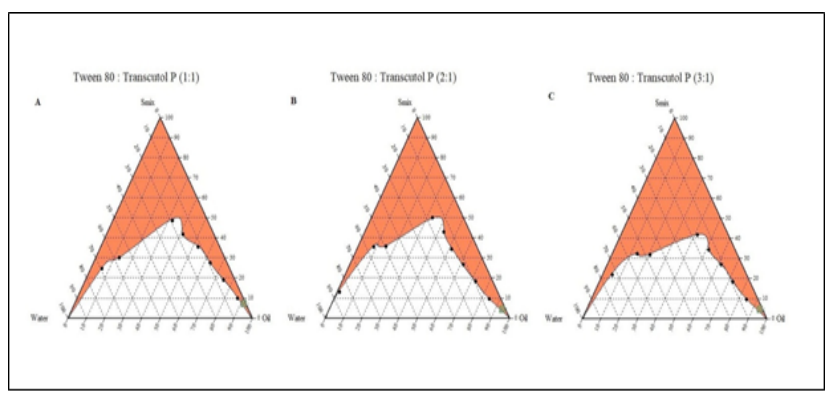

Figure 2: Pseudo-ternary phase diagrams of MEs comprising of Capryol ${ }^{\mathrm{TM}}$ 90, Smix (Tween 80: Transcutol ${ }^{\circledR} \mathrm{P}$ ) and water at various oil: Smix ratios; (A) 1:1, (B) 2:1, (C) 3:1. 
oil and surfactant in the formulation can cause toxicity and skin irritation. It should be determined properly and an optimum concentration should be used. The maximum safe concentration of Smix was selected as $60 \%$. In the present study, blank microemulsions were prepared at 5-30\% oil, 30-60\% Smix and $35-65 \%$ water by water titration method.

\section{Evaluation of the microemulsions}

Among the formulated blank microemulsions the microemulsions M5 5\%, M6 5\%, M7 5\%, M4 10\%, M5 $10 \%$ and M6 10\% were found to be clear, stable and had appreciable viscosity.

These blank microemulsion formulae were formulated into drug loaded microemulsions and were further evaluated.

\section{Evaluation of etoricoxib loaded microemulsions}

The drug loaded microemulsions did not show any physical changes such as phase separation or precipitation. They were clear transparent liquids with a homogenous appearance and a yellow tinge.

\section{Qualitative test}

Upon dilution microemulsions were clear and did not show phase separation or precipitation indicating that the microemulsions were $\mathrm{o} / \mathrm{w}$ type.

In dye test, the water-soluble dye (methylene blue) that was added to the microemulsions got rapidly dispersed throughout the microemulsions indicating that they were o/w type of microemulsions.

The percent transmittance of the drug loaded microemulsions and the microemulsions after dilution were close to $100 \%$ indicating that the microemulsions were clear and transparent.

The viscosity of the microemulsions was found to be in the range of $72 \pm 0.577 \mathrm{cps}$ and $127 \pm 1.000 \mathrm{cps}$ and increased with the increase in concentration of the surfactant and cosurfactant.

The $\mathrm{pH}$ range accepted for dermal preparations is 4-7 i.e. close to the $\mathrm{pH}$ of the skin. The $\mathrm{pH}$ of all the systems lied within the limit.

The drug content of the formulations was found to be in the range of $90.43 \pm 0.907$ to $98.03 \pm 0.611$ with formulation M7 5\% having the highest amount of drug content.

When subjected to centrifugation, drug loaded microemulsions did not show any signs of phase separation or precipitation thereby confirming the stability of the microemulsions.

\section{Droplet size, polydispersity index and zeta potential measurement}

The concentration of the oil phase in the formulated microemulsion affected the globule size. The average globule size increased with the increase in the concentration of the oil. The smaller globule size of microemulsion was obtained due to the higher concentration of surfactant and cosurfactant in microemulsion system. The decrease in the globule size can be attributed to the solubilization of internal phase within a larger number of surfactant micelles, which are consequently swollen to a lesser extent. PDI varies from 0.0 to 1.0 and is a measure of particle homogeneity. The particles are more homogenous if the PDI value is closer to zero. The PDI of the formulations was found to be less than 1 and indicated acceptable homogeneity. The zeta potential of the formulations was found to have a negative charge. Due to the slight negative charge of the droplets, aggregation is less likely to happen. The results

\begin{tabular}{|c|c|c|}
\multicolumn{2}{|c|}{ Table 2: Emulsification study on surfactant and } \\
cosurfactant. \\
\hline Sr. No. & Dispersion & $\begin{array}{c}\text { Percent } \\
\text { transmittance (Mean } \\
\pm \text { SD, } \boldsymbol{n}=3 \text { ) }\end{array}$ \\
\hline 1. & For surfactant & $99.8 \pm 0.058$ \\
\hline 2. & For cosurfactant & $99.8 \pm 0.115$ \\
\hline
\end{tabular}

\begin{tabular}{|c|c|c|c|}
\hline \multicolumn{4}{|c|}{ Table 3: Results of particle size, zeta potential and } \\
polydispersity index. \\
\hline Formulation & $\begin{array}{c}\text { Particle size } \\
(\mathbf{n m})\end{array}$ & $\begin{array}{c}\text { Zeta potential } \\
(\mathbf{m V})\end{array}$ & $\begin{array}{c}\text { Polydispersity } \\
\text { index }\end{array}$ \\
\hline M5 5\% & $35.14 \pm 0.3$ & $-0.187 \pm 0.012$ & $0.327 \pm 0.006$ \\
\hline M6 5\% & $17.78 \pm 0.5$ & $-1.11 \pm 0.04$ & $0.250 \pm 0.002$ \\
\hline M7 5\% & $37.61 \pm 0.2$ & $-2.88 \pm 0.03$ & $0.162 \pm 0.005$ \\
\hline M4 10\% & $178.7 \pm 0.1$ & $-1.20 \pm 0.24$ & $0.521 \pm 0.014$ \\
\hline M5 10\% & $161.0 \pm 0.4$ & $-1.70 \pm 0.011$ & $0.312 \pm 0.001$ \\
\hline M6 10\% & $128.0 \pm 0.1$ & $-2.03 \pm 0.19$ & $0.301 \pm 0.008$ \\
\hline
\end{tabular}
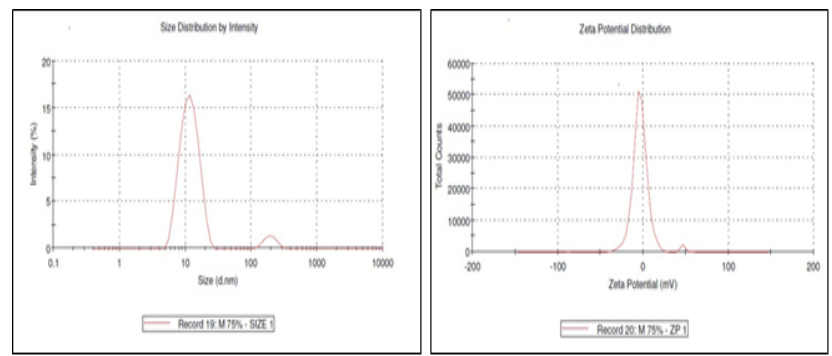

Figure 3: Graph of (A) particle size and (B) zeta potential of formulation M7 5\%. 


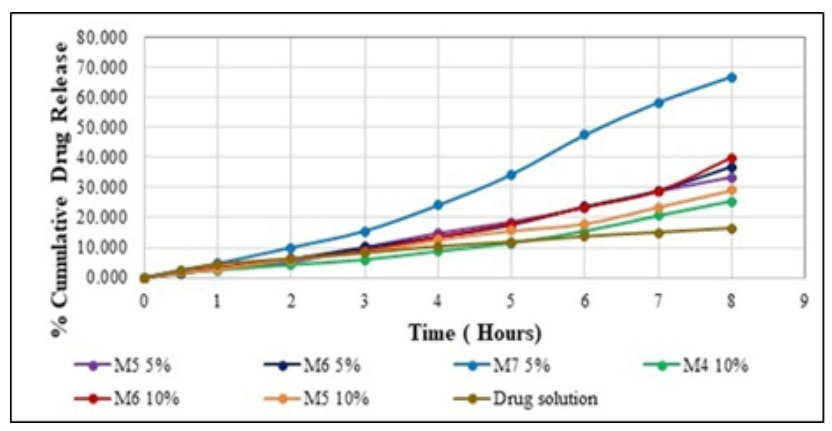

Figure 4: Graph of cumulative drug release vs time of selected microemulsion formulations and drug solution.

of particle size, zeta potential and polydispersity index are depicted in Table 3. Formulation M7 5\% was found to have satisfactory results and is depicted in Figure 3 (A) and 3 (B).

\section{In vitro drug release}

The in vitro release profile of the drug from the selected microemulsions and drug solution is depicted in Figure 4. This study was performed to find out the amount of drug released by the formulation and the results were compared with that of the pure drug solution. The optimum formulation M7 5\%, showed a release of $66.82 \%$ in $8 \mathrm{hr}$ indicating that the diffusion was increased with the use of a higher ratio of surfactant mixture. The formulated microemulsions showed a higher release as compared to the drug solution. This may be due to the solubility enhancing capacity of the surfactant and cosurfactant.

From the above tests carried out on the ETO microemulsions formulation M7 5\% was found to exhibit superior results and was therefore selected as the optimized formulation.

\section{Stability studies}

The optimized microemulsion were found to be stable. No significant deviations were observed at $40^{\circ} \mathrm{C} / 75 \%$ $\mathrm{RH}$ in 3 months' time.

\section{Formulation and development of etoricoxib microemulsion based gel}

The optimized microemulsion M7 5\% was incorporated into the gel base to form a microemulsion based gel.

\section{Evaluation of etoricoxib microemulsion based gel}

The prepared microemulsion based gel was found to have a glossy appearance with a smooth and homogenous texture. The gel was clear with a gel consistency and no phase separation was observed.

The viscosity of the etoricoxib loaded microemulsion based gel was found to be $9742 \pm 63.592$ cps.
The $\mathrm{pH}$ of the microemulsion based gel of etoricoxib was found to be $6.75 \pm 0.015$ which is equivalent to the $\mathrm{pH}$ of the skin and is therefore suitable for topical application.

In spreadability test, the diameter was found to be $6.8 \pm$ $0.021 \mathrm{~cm}$ which is indicative of good spreadability.

The etoricoxib content of the microemulsion based gel was found to be $97.6 \pm 0.458 \%$ of the theoretical value. The amount of drug released after $8 \mathrm{~h}$ from the microemulsion based gel was found to be $57.804 \pm 0.561 \%$ indicating slow release

\section{Kinetic modelling of in vitro release results}

The regression coefficient for zero order, first order and Higuchi model was found to be $0.9327,0.8384$ and 0.8404 . It can be deduced that the microemulsion based gel follows zero order kinetics due to the higher correlation coefficient of the zero-order plot as compared to that of the first order plot. The correlation coefficient is close to 1 indicating that the formulations exhibit diffusion mechanism in drug release and is suitable for modified release formulations. The data was subjected to Korsmeyer-peppas plot and the ' $n$ ' value was found to be higher than 0.89 indicating that the formulation exhibits super case II transport type of diffusion.

\section{Ex vivo permeation studies}

The ex vivo permeation studies was carried out on the microemulsion based gel and was found to be 49.191 $\pm 0.622 \%$ which is comparable with earlier results of in vitro studies.

\section{Stability studies}

The results of the stability studies of the microemulsion based gel showed no significant change in physical appearance, viscosity, $\mathrm{pH}$, drug content and in vitro release after 3 months of storage at accelerated conditions of temperarure and humidity.

\section{CONCLUSION}

The microemulsion based drug delivery system of ETO was successfully prepared by initially formulating a microemulsion comprising of $\mathrm{Capryol}^{\mathrm{TM}} 90$, Tween 80 and Transcutol ${ }^{\circledR} \mathrm{P}$ as the oil, surfactant and cosurfactant respectively. The microemulsion was then incorporated into a $1 \%$ Carbopol $^{\circledR} 934$ gel base. The formulated microemulsion based gel of ETO has a potential for the transdermal delivery of the drug thereby overcoming the complications associated with the oral administration of the drug. The in vitro release of the drug from the microemulsion based gel was much higher than that of the drug solution. Thus, this study demonstrated 
that the microemulsion based gel formulation can be employed to improve the solubility and skin permeability of etoricoxib.

\section{ACKNOWLEDGEMENT}

The authors would like to acknowledge Sanofi India Limited, Verna - Goa (India) for the gift sample of the drug etoricoxib, Gatefosse' India, for the free samples of Capryol ${ }^{\mathrm{TM}}$ 90, Transcutol ${ }^{\circledR} \mathrm{P}$ and Centaur Pharmaceuticals, Goa (India) for Cremophor ${ }^{\circledR}$ RH 40 gift sample. The authors would also like to thank the Goa College of Pharmacy, Government of Goa (India).

\section{CONFLICT OF INTEREST}

The authors have no conflict of interest

\section{ABBREVIATIONS}

NSAID: Non steroidal antiinflammatory drug; MP'S: Microparticles; v/v: Volume/volume; UV: Ultraviolet; UK: United Kingdom; RH: Relative Humidity; IAEC: Institutional Animal Ethics Committee; PDI: Polydispersity Index; ETO: Etoricoxib; o/w: Oil in water.

\section{REFERENCES}

1. Firestein GS. Immunologic mechanisms in the pathogenesis of rheumatoid arthritis. Journal of Controlled Release. 2005;11(3):S39-44.

2. Gabriel SE. The epidemiology of rheumatoid arthritis. Rheumatic Disease Clinics. 2001;27(2):269-81.

3. Walker R, Whittlesea C. Clinical Pharmacy and Therapeutics. $5^{\text {th }}$ ed. Edinburg: Churchill Livingstone Elsevier. 2012.

4. Rang HP, Dale MM, Ritter JM, Flower RJ. Rang and Dale's pharmacology. $6^{\text {th }}$ ed. London: Elsevier Health Sciences; 2007.

5. Brahmankar DM, Jaiswal SB. Biopharmaceutics and pharmacokinetics: A treatise. Delhi: Vallabh Prakashan; 2005.

6. Tripathi KD. Essentials of medical pharmacology. $7^{\text {th }}$ ed. New Delhi: Jaypee Brothers Medical Publishers (P) Ltd; 2013.

7. Patel V, Kukadiya H, Mashru R, Surti N, Mandal S. Development of microemulsion for solubility enhancement of clopidogrel. Iranian Journal of Pharmaceutical Research. 2010;9(4):327-34.

8. Kathpalia H, Patravale VB, Sharma K. Development and evaluation of a microemulsion formulation for transdermal delivery of Diclofenac diethylammonium. Journal of Scientific and Innovative Research. 2013;2(4):759-71.

9. Mehta DP, Rathod HJ, Shah DP, Shah CN. A review on microemulsion based gel: A recent approach for topical drug delivery system. Research Journal of Pharmacy and Technology. 2015;8(2):118-26.

10. Khan MR, Hussain M, Raza SM, Nazir SR. Formulation development evaluation and anti-inflammatory effects of etoricoxib cream. Indo American Journal of Pharmaceutical Research. 2014;4(10):3945-52.
11. Prakash PR, Rao NR, Chowdary S. Formulation, evaluation and antiinflammatory activity of topical etoricoxib gel. Asian Journal of Pharmaceutical and Clinical Research. 2010;3(2):126-9.

12. Sailaja AK, Begum N. Formulation and evaluation of cox-2 inhibitor (etoricoxib) loaded ethyl cellulose nanoparticles for topical drug delivery. Nano Biomedicine and Engineering. 2018;10(1):1-9.

13. Raghuwanshi S, Kadu BS. Transdermal delivery of etoricoxib through ethosomal formulation: An ingenious approach towards treatment of skin inflammation. Journal of Drug Delivery Science and Technology. 2017;40:95104.

14. Arunkumar P, Indulekha S, Vijayalakshmi S, Srivastava R. Poly (caprolactone) microparticles and chitosan thermogels based injectable formulation of etoricoxib for the potential treatment of osteoarthritis. Materials Science and Engineering C. 2016;61:534-44.

15. Senthilkumar K, Vijaya C. Formulation development of mouth dissolving film of etoricoxib for pain management. Advances in Pharmaceutics. 2015:1-11.

16. Lala RR, Awari NG. Nanoemusion-based gel formulations of COX-2 inhibitors for enhanced efficacy in inflammatory conditions. Applied Nanoscience. 2014;4(2):143-51.

17. Ashara KC, Paun JS, Soniwala MM, Chavda JR, Mendapara VP, Mori NM. Microemulgel: An overwhelming approach to improve therapeutic action of drug moiety. Saudi Pharmaceutical Journal. 2016;24(4):452-7.

18. Yadav V, Jadhav P, Kanase K, Bodhe A, Dombe S. Preparation and evaluation of microemulsion containing antihypertensive drug. International Journal of Applied Pharmaceutics. 2018;10(5):138-46.

19. Shinde U, Pokharkar S, Modani S. Design and evaluation of microemulsion gel system of nadifloxacin. Indian Journal of Pharmaceutical Sciences. 2012;74(3):237-47.

20. Shah V, Gandhi K, Parikh R, Sharma M, Suthar V. Quality by Design (QbD) approach for optimization of microemulsion based topical gel. Marmara Pharmaceutical Journal. 2016;20(3):415-24.

21. Moghimipour E, Salimi A, Leis F. Preparation and evaluation of tretinoin microemulsion based on pseudo-ternary phase diagram. Advanced Pharmaceutical Bulletin. 2012;2(2):141.

22. Fouad SA, Basalious EB, El-Nabarawi MA, Tayel SA. Microemulsion and poloxamer microemulsion-based gel for sustained transdermal delivery of diclofenac epolamine using in-skin drug depot: In vitrolin vivo evaluation. International Journal of Pharmaceutics. 2013;453(2):569-78.

23. Kansagra $\mathrm{H}$, Mallick $\mathrm{S}$. Microemulsion-based antifungal gel of luliconazole for dermatophyte infections: Formulation, characterization and efficacy studies. Journal of Pharmaceutical Investigations. 2016;46(1):21-8.

24. Solanki SS, Sarkar B, Dhanwani RK. Microemulsion drug delivery system: For bioavailability enhancement of ampelopsin. ISRN Pharmaceutics. 2012;108164.

25. Stability testing of new drug substances and products Q1A-Q1F Stability. 2018. Cited 30 March 2018]. Available from: http://www.ich.org/products/ guidelines/quality/quality-single/article/stability-testing-of-new-drugsubstances-and-products.html.

26. Bachhav YG, Patravale VB. Microemulsion based vaginal gel of fluconazole: Formulation, in vitro and in vivo evaluation. International Journal of Pharmaceutics. 2009;365(1-2):175-9.

27. Sabale V, Vora S. Formulation and evaluation of microemulsion-based hydrogel for topical delivery. International Journal of Pharmaceutical Investigations. 2012;2(3):140-9.

28. Barot BS, Parejiya PB, Patel HK, Gohel MC, Shelat PK. Microemulsionbased gel of terbinafine for the treatment of onychomycosis: Optimization of formulation using D-optimal design. AAPS Pharm Sci Tech. 2012;13(1):18492. 
PICTORIAL ABSTRACT

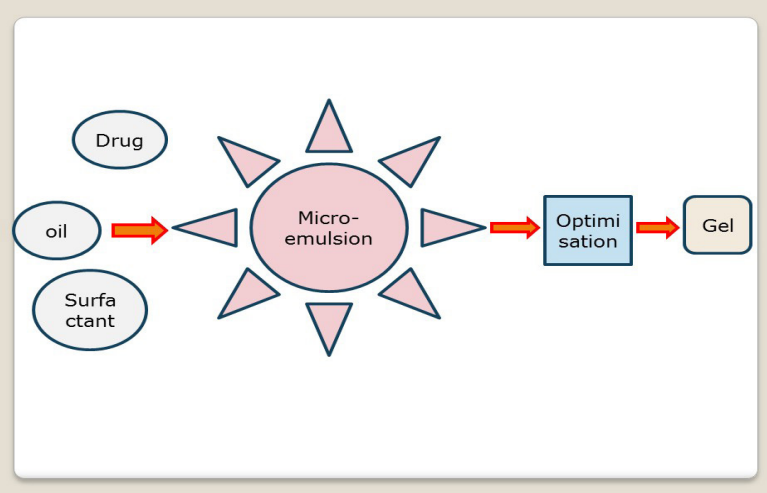

\section{About Authors}

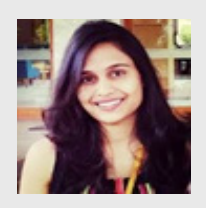

Ms. Vania Fonseca has done her B. Pharm. and M. Pharm. (Quality Assurance) from Goa College of Pharmacy (GCP), Panaji Goa under Goa University in year 2015 and 2018 respectively. She is presently working in Project Management Dept. at VerGo Pharma Research Lab, Verna Goa.

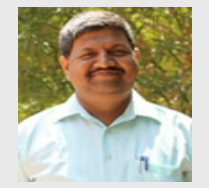

Dr. Prashant Jivaji Bhide is working as Professor and HOD, Department of Pharmaceutics, Goa College of Pharmacy (GCP), Panaji Goa. He has done his degree and PG in pharmacy from GCP and Ph. D. in Pharmaceutical Sciences from MAHE (former Manipal University). He has about 21 years of experience in teaching, 15 years in research and 3 years in pharma industry. He has successfully guided $16 \mathrm{M}$ Pharm QA students at GCP.

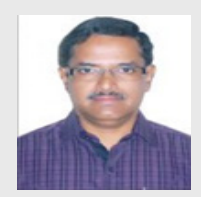

Dr. Madhusudan Joshi is working as Professor and HOD, Department of Pharmacology, Goa College of Pharmacy (GCP), Panaji Goa. He has done his degree and PG in pharmacy from GCP and Ph. D. from Mumbai University in year 2004. He has about 26 years of experience in teaching, 20 years in research and 6 years in pharma industry. He is recognized as PG and Ph. D. guide at Goa University. He has successfully guided $34 \mathrm{M}$ Pharm pharmacology students and presently guiding one Ph. D. student at GCP.

Cite this article: Fonseca V, Bhide PJ, Joshi MP. Formulation, Development and Evaluation of Etoricoxib Nanosize Microemulsion Based Gel for Topical Drug Delivery. Indian J of Pharmaceutical Education and Research. $2019 ; 53(4 s): s 571-s 579$. 